\title{
Variability of hydrogen defects in mantle orthopyroxene along a back- arc transect in Southern Patagonia
}

\author{
ALEXANDRA DEMERS-ROBERGE ${ }^{1}$, MICHAEL C. \\ JOLLANDS $^{2}$, PETER M TOLLAN ${ }^{3}$ AND OTHMAR \\ MÜNTENER $^{4}$
}

\author{
${ }^{1}$ Université de Lausanne \\ ${ }^{2}$ Lamont Doherty Earth Observatory \\ ${ }^{3}$ Institute of Geochemistry and Petrology, ETH Zürich \\ ${ }^{4}$ University of Lausanne \\ Presenting Author: alexandra.demers-roberge@unil.ch
}

In mantle xenoliths, the inter and intra-mineral distribution and speciation of $\mathrm{H}$ may record ambient mantle $\mathrm{H}$ budgets or interaction with the host magma. We measured $\mathrm{H}$ concentrations in orthopyroxenes from mantle xenoliths from eight different localities along a back-arc transect in Southern Patagonia, using Fourier transform infrared spectroscopy (FTIR). In these samples, we distinguish two different types of spectra, based on the relative absorbance of the $3590 \mathrm{~cm}^{-1}$ peak in comparison to the $3570 \mathrm{~cm}^{-1}$ peak: 1) $\mathrm{Abs}_{3590} / \mathrm{Abs}_{3570}>1$, 2) $\mathrm{Abs}_{3590} / \mathrm{Abs}_{3570}<$ 1. All groups have absorbance bands at $3515 \mathrm{~cm}^{-1}$ and $3410 \mathrm{~cm}^{-1}$, and sometimes, at $3310 \mathrm{~cm}^{-1}$ and $3085 \mathrm{~cm}^{-1}$. The results show variability between the different localities, within the same xenolith suites from a single locality, and also within the same xenolith sample, and the same crystal. The position of the different bands represents characteristic defects in which hydrogen is incorporated. Therefore, we used mineral major and trace elements contents to calculate thermodynamic parameters and indicators of metasomatism to investigate potential systematics related to the characteristic bands of the FTIR spectra. The combination of experimental peak attribution to defects and crystal scale observations suggests that a large concentration of $\mathrm{R}^{3+}$ (generic trivalent) cation defects relative to Si-vacancies due to intrinsic characteristics or external parameters could explain most of the differences in the FTIR spectra. At a larger scale, no clear correlation was observed between metasomatic indicators $\left(\mathrm{Ti}, \mathrm{Na}, \mathrm{Th}, \mathrm{Li},(\mathrm{La} / \mathrm{Sm})_{\mathrm{N}}\right)$, temperature or $f_{\mathrm{O} 2}$, but a correlation between the concentration of $\mathrm{R}^{3+}$, mostly $\mathrm{Al}^{3+}$, and the different types of spectra was observed, suggesting that a higher concentration of $\mathrm{R}^{3+}$ favors specific $\mathrm{R}^{3+}$-related absorption bands. The highly variable inter and intra-crystal $\mathrm{H}$ concentrations and $\mathrm{H}$ defects and lack of correlation with metasomatic indicators indicates rapid timescales of $\mathrm{H}$ modification prior to magma entrainment, with a dominant control from orthopyroxene solid solution composition. Our data indicates that combining crystal composition, total mineral $\mathrm{H}$ content and defect-specific $\mathrm{H}$ content are key to understanding the processes modifying mantle $\mathrm{H}$ concentrations. 